\title{
Análise temporal da incidência da hepatite A no município de Belém-Pa, Brasil, nos anos de 2008 e 2009 e disseminação da informação na ilha de Cotijuba
}

\author{
Lena P. S. Rodrigues ${ }^{1}$, Douglas Gasparetto ${ }^{2}$, João J. B. Monteiro ${ }^{3}$, Nelson F.L. \\ Soffiatti $^{4}$, Nelson Veiga ${ }^{5}$ \\ ${ }^{1}$ Instituto Evandro Chagas/SVS/MS, Laboratório de Geoprocessamento, \\ lpsrd13@gmail.com \\ ${ }^{2}$ Instituto Evandro Chagas/SVS/MS, Laboratório de Geoprocessamento, \\ douglaslabgeo@gmail.com \\ ${ }^{3}$ Instituto Evandro Chagas/SVS/MS, Laboratório de Geoprocessamento, \\ jjomonteiro@gmail.com \\ ${ }^{4}$ Instituto Evandro Chagas/SVS/MS, Laboratório de Geoprocessamento, \\ nelsonsoffiatti@iec.pa.gov.br \\ ${ }^{5}$ Instituto Evandro Chagas/SVS/MS, Laboratório de Geoprocessamento, \\ nelsoncg2009@gmail.com
}

\begin{abstract}
Resumo. A análise de dados epidemiológicos, ambientais e sócio-econômicos foi modelada para reconhecer os fatores temáticos da Hepatite $A$ e seus mecanismos de disseminação, na ilha de Cotijuba, onde os casos ocorridos em 2008 e 2009 foram indistintamente notificados em Belém - PA. Para reconhecer a existência desses fatores foram utilizadas geotecnologias emergentes associadas a estruturas de dados relacionais e não relacionais com o método de análise temporal da relação entre os fatores e a incidência da hepatite A, naquela área de estudos. Alguns dos elementos temáticos identificados são controláveis com ações locais. Essa constatação gerou conhecimentos aplicáveis ao cenário ecoepidemiológico da hepatite A, existente na ilha, os quais foram repassados aos Agentes Comunitários de Saúde, durante a oficina realizada pelo Laboratório de Geoprocessamento do Instituto Evandro Chagas, no XIII IFNOPAP \& III CAMPUS FLUTUANTE, promovido pela Universidade Federal do Estado do Pará.
\end{abstract}

\section{Introdução}

A hepatite A é um grave problema de saúde pública no mundo, observado principalmente na periferia das cidades e, nos casos mais graves, pode ser fatal. É uma doença infectocontagiosa e aguda, causada pelo vírus HAV e ataca o fígado. A transmissão é do tipo fecal-oral, de pessoa para pessoa ou através do contato com alimentos e água contaminada, que é um dos veículos de disseminação do vírus. O vírus da hepatite A pode sobreviver de 12 semanas até 10 meses em água; moluscos e crustáceos podem retê-los até 15 vezes mais do que a água [FERREIRA; SILVEIRA, 2004].

No Brasil, há índices elevados de incidência de Hepatite A, nos centros urbanos e na periferia das cidades. Na região norte do Brasil, no estado do Pará, a incidência tem-se mantido alta, principalmente em crianças em idade escolar, constituindo-se em um problema de saúde pública que produz alta morbidade e baixa resistência orgânica facilitando a instalação de outros agravos, conforme dados do Ministério da Saúde (2005). 


\section{Revista TECCEN - volume 3 - número 1 - abril de 2010 - ISSN 1984-0993}

Diante do contexto Epidemiológico, a epidemiologia estuda as relações entre o agravo e os contextos de vida das populações humanas; utiliza a habilidade técnica para categorizar e explicar parte das relações entre os elementos locais e o processo de saúdedoença, em razão das variações regionais da endemicidade.

As análises incorporaram tecnologias de outros campos do conhecimento, aplicáveis às questões ambientais e sócio-econômicas. Dentre elas, as geotecnologias aplicadas às análises espaço-temporais - técnicas de Geoprocessamento, Geoestatística e Banco de Dados Geográficos - consideradas expressivas por Veiga (2005), permitem reconhecer atributos espaço-temporais e correlacioná-los às alterações em ecossistemas naturais, através das análises geoestatísticas [Medronho 1999 e Dias et al. 2004]. Para Druck et. al (2004: p.01) essa interpretação é um desafio tecnológico em diversas áreas do conhecimento.

Com esses recursos a Epidemiologia pode manipular dados discretos e contínuos, que guardam relação de dependência espacial entre si, afirmação reforçada por Ortiz (2003: p. 02), ao considerar que as técnicas de geoestatística e estatística clássica, agregadas ao geoprocessamento, possibilitam tratar, correlacionar, sobrepor, analisar e visualizar as informações espaciais, na forma de mapas digitais. Esse processo pode acelerar decisões, minimizar custos sociais e trazer produtividade para os recursos de saúde. Esta última etapa foi alcançada com o uso sistemático de Sistemas de Informação Geográfica - SIGs [Smith et. al. 1988 e Burrough et. al. 1998].

Neste sentido, a análise de dados sócio-econômicos, ambientais e epidemiológicos gerou conhecimento aplicável ao cenário ecoepidemiológico relativo à temática da Hepatite A, na ilha de Cotijuba, aspecto aqui apresentado na abordagem técnica da modelagem e metodologia utilizada na execução do trabalho de campo e geração do sistema.

\section{Metodologia}

\subsection{Caracterização da área de estudo}

A área integra o perímetro insular do município de Belém, estado do Pará, em ambiente estuarino, situado no quadrante Sul da baía do Marajó, juntamente com as ilhas Jutuba, Paquetá e Tatuóca, separando a baía do Guajará e o rio Pará (SEPOF, 2008), conforme Figura 1. A ilha de Cotijuba possui $16.000 \mathrm{~km}^{2}$, altitude entre 0 e 10 metros e população em rápida evolução: 637 habitantes (IBGE, 1991, apud Mascarenhas 2009) e 4.000 (CODEM, 1997 apud Mascarenhas 2009) diferenças atribuídas às transformações locais recentes. A cobertura vegetal original é a floresta de terra firme, mata secundária, campos e igapós. O solo predominante é latossolo amarelo arenoso. O clima é condicionado pelo estuário com temperaturas médias anuais entre $24^{\circ} \mathrm{C}$ e $33^{\circ} \mathrm{C}$, umidade relativa do ar entre $80 \%$ e $90 \%$; precipitações média anual $2.800 \mathrm{~mm}$, período chuvoso de dezembro a junho e estiagem de julho a novembro [MASCARENHAS et al. 2009].

A atividade econômica, na ilha de Cotijuba tem perfil primário básico constituído por práticas de pesca artesanal, agricultura de subsistência, extrativismo vegetal e mais recentemente turismo de visitação, Melo (2008).

A urbanização não planejada apresenta inadequações de infraestrutura para destinação de lixo e esgotamento sanitário, registrando-se esforços da comunidade nesse 


\section{Revista TECCEN — volume 3 - número 1 - abril de 2010 - ISSN 1984-0993}

sentido (Nascimento, 2002). "O padrão de construções é estratificado segundo a ocupação dos segmentos populacionais: cobertura de palha (30 e 23\%, para agricultores e pescadores, respectivamente), de cimento amianto (12,5 e 32,9\%), piso de terra batida $(45,8$ e $20,7 \%)$ e madeira $(16,7$ e $58,5 \%)$ indicam a rusticidade das habitações. O indicador mais agravante da insalubridade - para a hepatite A e outros agravos infectocontagiosos, entretanto se encontra no tipo de água utilizada, indisponível para mais de $25 \%$ de agricultores e pescadores, sendo o poço manual a principal fonte. Quanto aos equipamentos sanitários, o quadro é de $87,5 \%$ de agricultores e $95,1 \%$ de pescadores com fossa negra ou nenhum equipamento, significando um nível de exposição elevado à contaminação, uma vez que estas práticas são inadequadas e não recomendáveis do ponto de vista sanitário'. (Guerra 2002 apud Nascimento).

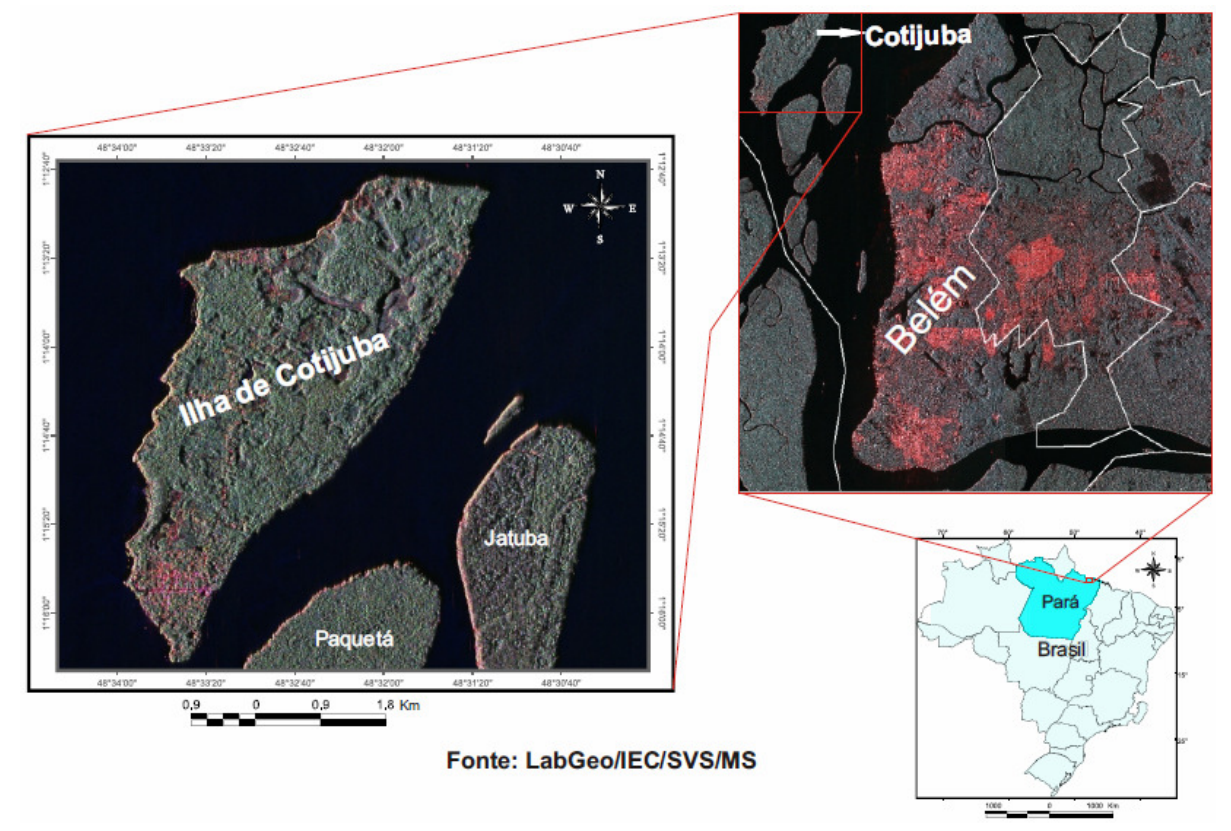

Figura 1. Mapa de localização do município de Belém e da llha de Cotijuba - PA.

\subsection{Procedimentos e materiais}

Os procedimentos metodológicos consistiram de revisão da literatura para a construção do referencial teórico e levantamento de informações referentes à incidência da hepatite A, na área de estudos, através do Sistema de Informação de Agravos de Notificação (SINAN) e na Secretaria Municipal de Saúde Pública de Belém (SESMA).

A certificação das informações em campo e a coleta de dados ocorram durante as oficinas do XIII IFNOPAP 2009, parte com os Agentes Comunitários de Saúde (ACS).

Os procedimentos laboratoriais utilizaram o software Spring 4.0 para o préprocessamento das imagens de satélite, composição colorida de bandas espectrais e ampliação linear de contraste; o software ArcGis 9.3 para a álgebra de mapas e interrelacionamento das bases de dados georreferenciadas - imagens do satélite Landsat TM 5 e do sensor R99 SAR - e bases de dados ambientais, socioeconômicas, epidemiológicas e cartográficas, com que foram construídas as expressões visuais. Essas técnicas viabilizam precisão na localização dos dados.

Foi utilizada metodologia de comunicação social para retorno desta pesquisa à comunidade através de palestras, em oficina, para ACS`s da ilha de Cotijuba. Foi objetivo 


\section{Revista TECCEN — volume 3 - número 1 - abril de 2010 - ISSN 1984-0993}

reforçar noções básicas de prevenção da saúde, cuidados com a água e saneamento para transferir conhecimentos sobre o reconhecimento de locais e condições onde os riscos de contaminação podem ser maiores e como evitá-los.

\section{Resultados e Discussões}

Foram geradas expressões visuais dos bancos de dados georreferenciados em campo e das caracterizações socioeconômica e ambiental rápida, que identificaram as variáveis intervenientes na incidência da hepatite A, conforme Figura 2.

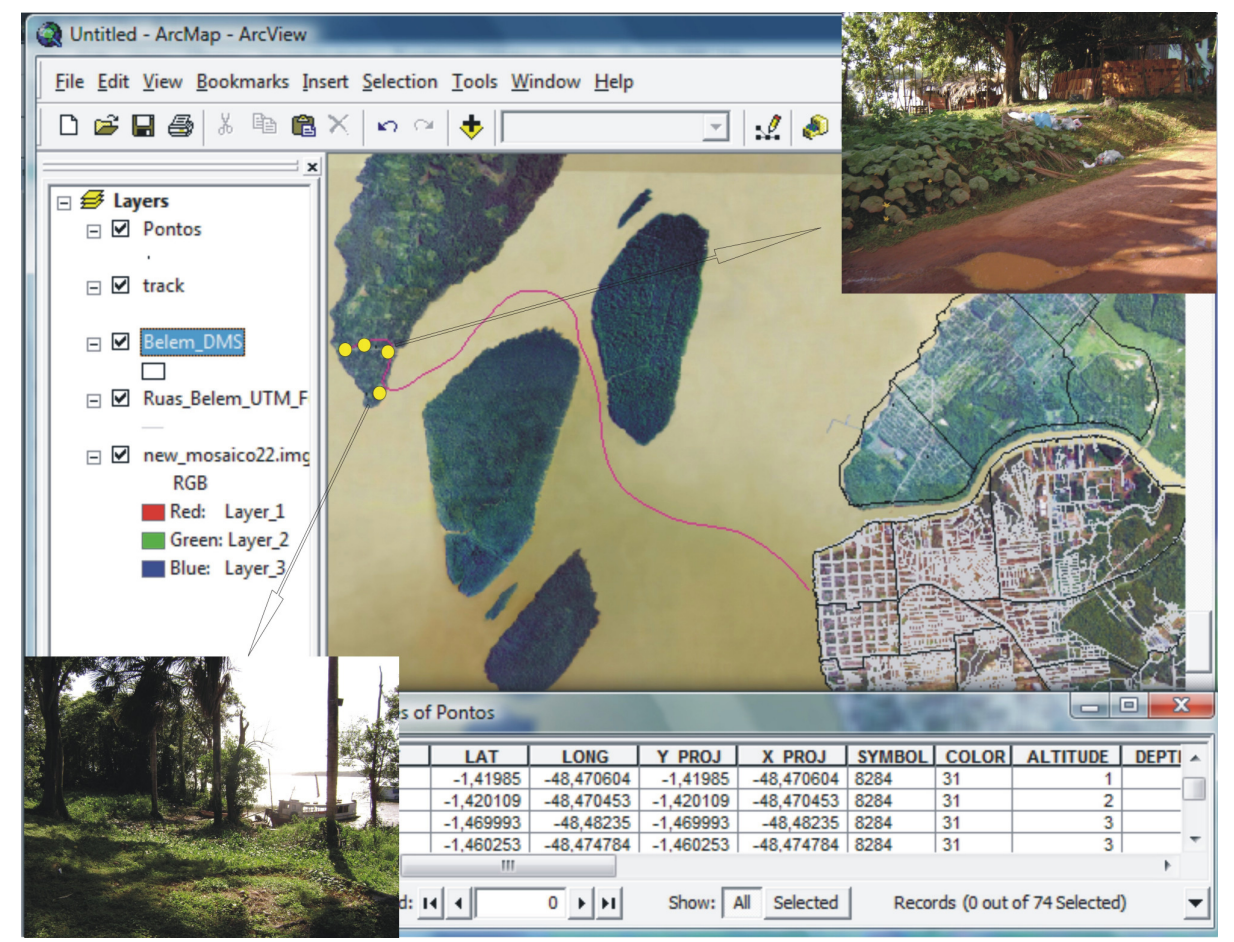

Figura 02. Interrelacionamento da imagem de satélite com os pontos de localização dos fatores temáticos, percursos e rota para a llha de Cotijuba. Fonte: LabGeo/IEC/SVS/MS.

Foram capturadas imagens relacionadas ao indivíduo, seu ambiente domiciliar e peridomiciliar, mostrando o acúmulo de lixo a céu aberto, em área urbana, conforme pode observado na figura 3 e 4 . 


\section{Revista TECCEN — volume 3 - número 1 - abril de 2010 - ISSN 1984-0993}

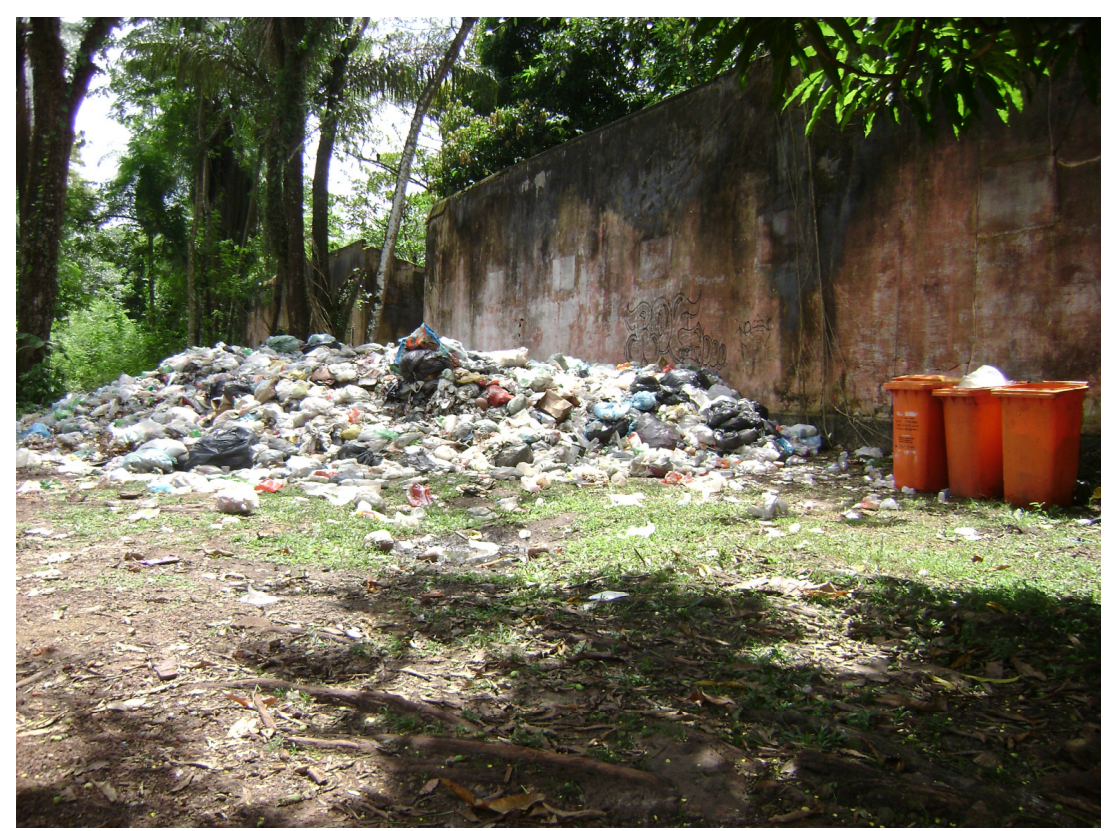

Figura 3. Deposito de lixo próximo da várzea. Fonte: LabGeo/IEC/SVS/MS.

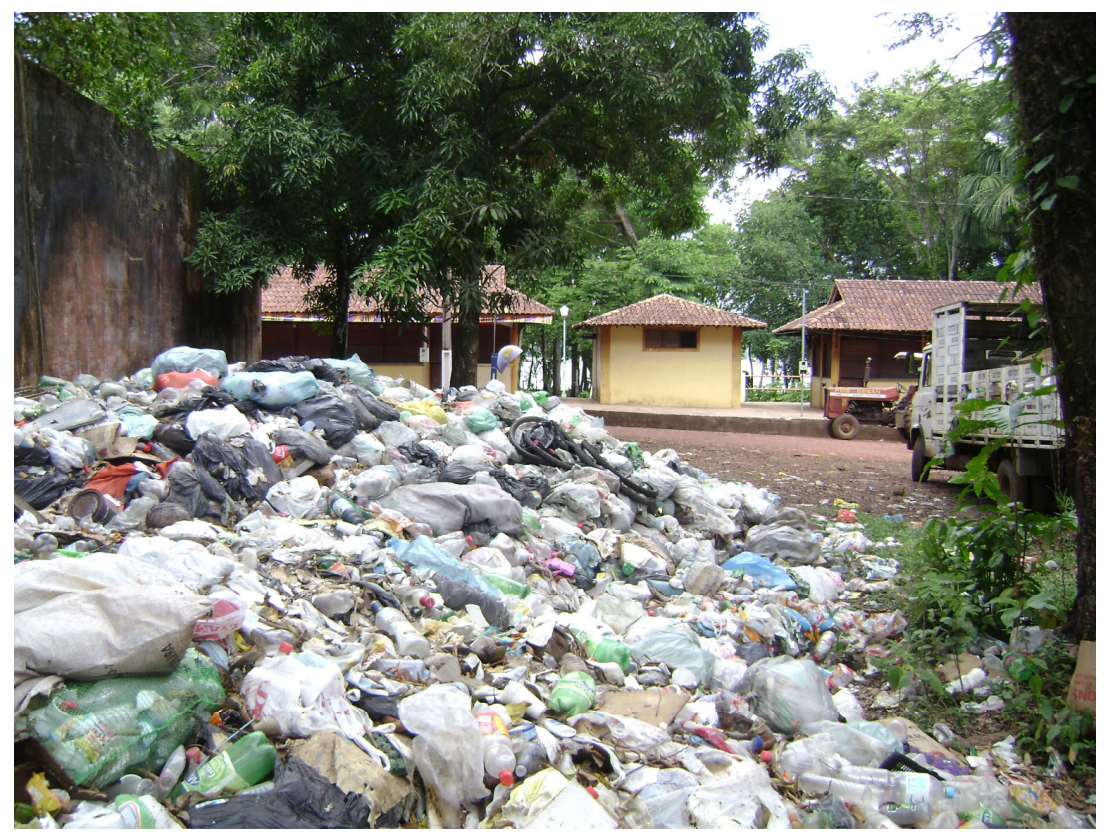

Figura 4. Lixo em área residencial. Fonte: LabGeo/IEC/SVS/MS.

O banco de dados com casos positivos para o HAV, no período de 2008 e 2009, está expresso em gráfico com a distribuição temporal da doença, onde foram registrados e confirmados 266 casos de Hepatite A, no município de Belém, conforme Figura 5. Os casos suspeitos em Cotijuba - encaminhados para Belém como inespecíficos - foram registrados com endereço no perímetro de ação da Unidade de Saúde onde o paciente foi atendido. A análise epidemiológica identificou essa distorção e motivou o estudo. 


\section{Revista TECCEN — volume 3 - número 1 - abril de 2010 - ISSN 1984-0993}

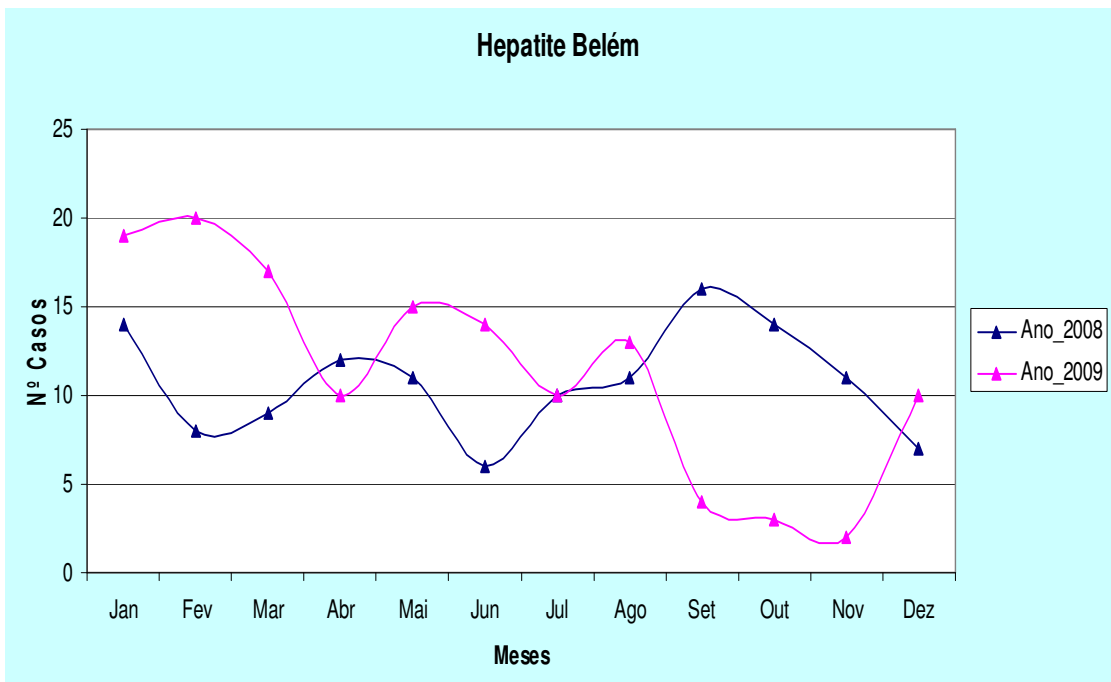

Figura 5 - Distribuição temporal dos casos confirmados de hepatite A, no município de Belém-Pa. Fonte: LabGeo/IEC/SVS/MS.

O lixo a céu aberto é fator de risco que impulsiona a incidência da doença, também favorecida pela cota altimétrica do terreno - média de 0 e 10 metros - na ilha de Cotijuba.

A permanência das condições sanitárias adversas (Guerra, 2002) e da tipologia econômica da ilha (Melo, 2008) caracteriza o risco coletivo identificado por Ferreira e Silveira (2004) para a transmissão da Hepatite A. O estudo atual identificou a permanência desses elementos temáticos alguns passíveis de controle com ações locais.

Essa constatação motivou a disseminação em programação inserida no XIII IFNOPAP, tendo por público alvo os ACS atuantes na Ilha de Cotijuba; a metodologia de palestra e oficina destacou a importância da sanidade ambiental e de informação para a comunidade, sobre os riscos encontrados na área urbana da ilha, ensejando cuidados com a água, higiene pessoal e saneamento, características socioeconômicas, epidemiológicas e ambientais que favorecem a incidência da Hepatite A, conforme figuras 6 e 7 .

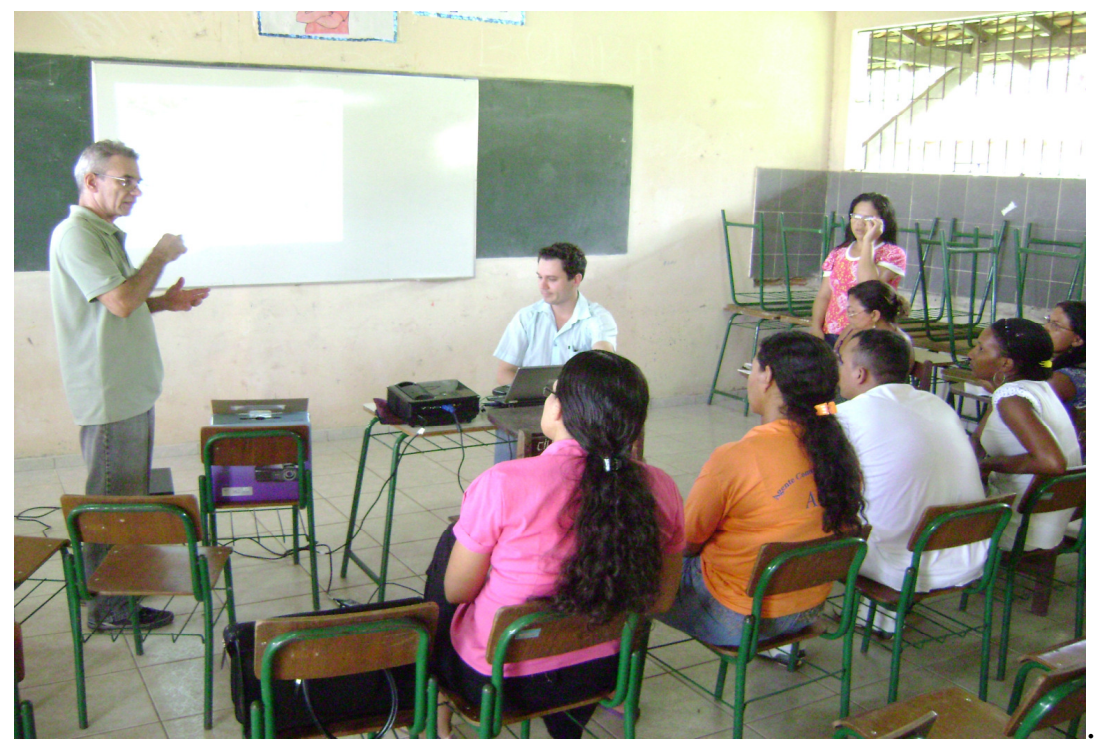

Figura 6. Palestra para os ACS sobre as características ecoepidemiológicas da área de estudo. Fonte: LabGeo/IEC/SVS/MS. 


\section{Revista TECCEN — volume 3 - número 1 - abril de 2010 - ISSN 1984-0993}

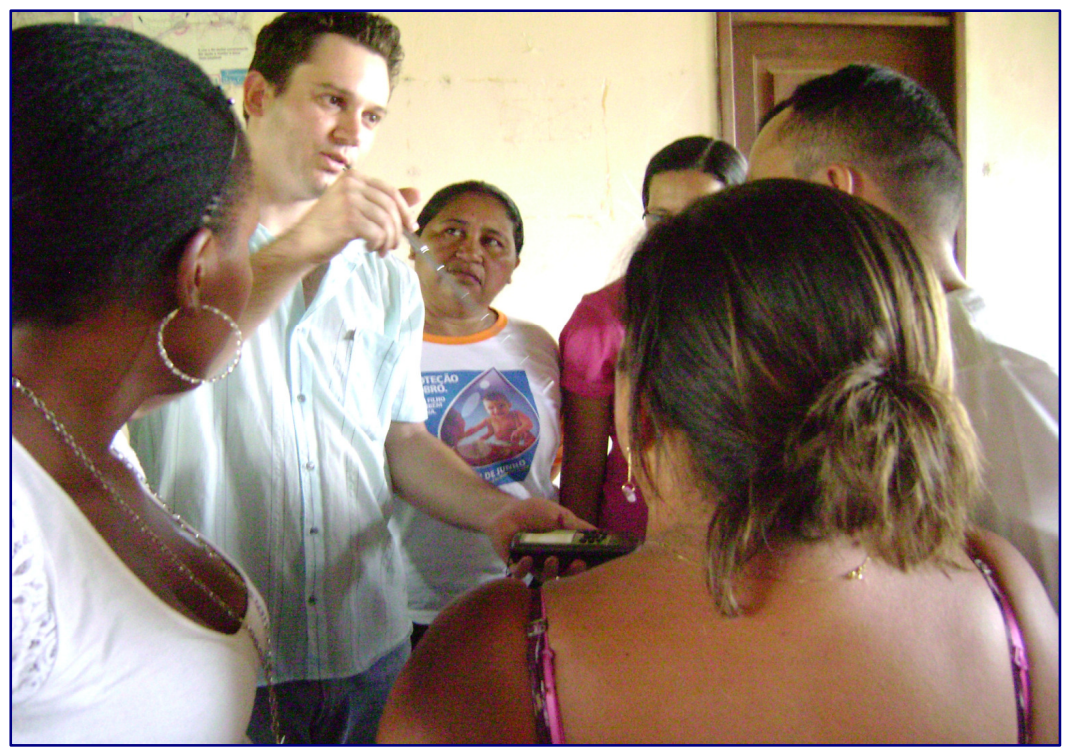

Figura 7. Exemplos da utilização de um sistema de informação para o georreferenciamento de dados precisos. Fonte: LabGeo/IEC/SVS/MS.

Durante a oficina, também foram realizadas palestras referente ao trabalho do Laboratório de Geoprocessamento do Instituto Evandro Chagas/SVS/MS e a contribuição do Geoprocessamento, como ferramenta de auxilio na elaboração de análises precisas de dados ecoepidemiológicos de agravos que incidem na região Amazônica, preconizado por Veiga (2001), conforme Figura 8.

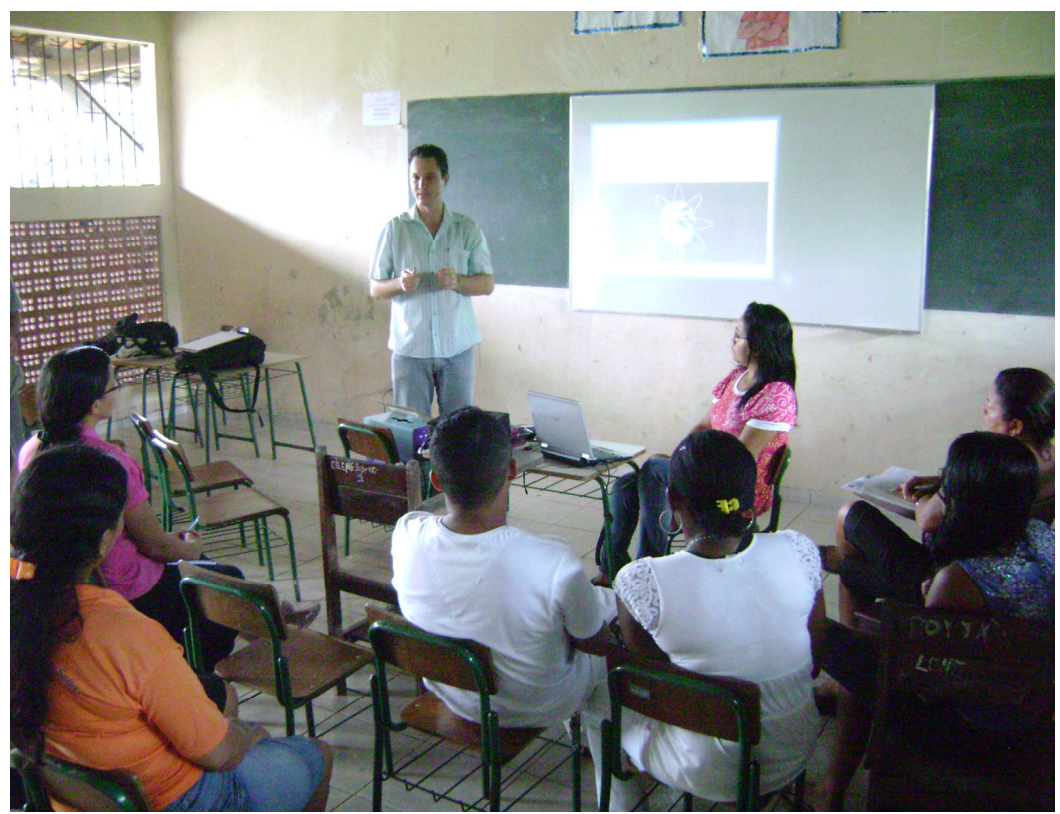

Figura 8. Palestra para os ACS mostrando as técnicas utilizadas para o desenvolvimento do estudo. Fonte: LabGeo/IEC/SVS/MS.

\section{Considerações Finais}

Levando em consideração os perfis socioeconômicos agregados ao presente estudo por Mascarenhas (2009) e Melo (2008) e confirmada sua permanência na área de estudos, foi observado que as condições favoráveis à disseminação da Hepatite A estão ativas na ilha de Cotijuba e tal fato merece atenção da vigilância epidemiológica local. 


\section{Revista TECCEN — volume 3 - número 1 - abril de 2010 - ISSN 1984-0993}

A utilização de geotecnologias livres com estruturas relacionais e não relacionais de informação produziu análises temporais da incidência desta doença identificando a existência de elementos temáticos possíveis de controlar com ações locais, as quais foram repassadas aos Agentes Comunitários de Saúde.

Foi observado que os casos ocorridos na área de estudo foram notificados em Belém - um hábito de pacientes do interior que se deslocam para a cidade; que as condições deficientes ou inexistentes de saneamento estão entre as principais causas que favorecem a disseminação da hepatite $\mathrm{A}$, também influenciada pela condição natural do ambiente e fatores antrópicos como educação sanitária e hábitos de higiene da população.

A expressão gráfica das séries temporais também permitiu identificar que o padrão de casos confirmados de Hepatite A, não guarda relação com a estiagem e as chuvas. É efeito considerável que merece análise pela possibilidade de ações de governo ou interferências que mudam o curso da doença.

Observado o perfil epidemiológico deste agravo, na região das ilhas menos desenvolvidas, há alta proporção de casos assintomáticos (informação verbal SEMA/Cotijuba), indicando necessidade de ferramentas e metodologias que auxiliem o diagnóstico desta doença.

\section{Referências Bibliográficas}

BURROUGH, P.A.; Mcdonnell, R.A. (1998) Principles of Geographic information systems. Oxford: University Press

DIAS, J.E. et al. (2004) Geoprocessamento aplicado à análise ambiental: o caso do município de Volta Redonda - RJ. In.: XAVIER DA SILVA, J.; ZAIDAN, R.T. (org.). Geoprocessamento \& análise ambiental: aplicações. Rio de Janeiro: Bertrand Brasil, Disponível em:<http://marte.dpi.inpe.br/col/dpi.inpe.br/sbsr@80/2006/11.15.13.35/ doc/2463-2470.pdf> Acesso em: 11 de jun 2008

DRUCK, S. et al. (2004) Análise Espacial de Dados Geográficos. Brasília, EMBRAPA, p. 1 (ISBN: 85-7383-260-6).

FERREIRA, C. T.; Silveira, T. R. (2004) Hepatites virais: aspectos da epidemiologia e da prevenção. Rev. bras. epidemiol., São Paulo, v. 7, n. 4, Available from $<$ http://www.scielo.br/scielo.php?script=sci_arttext\&pid=S1415-

790X2004000400010\&lng=en\&nrm=iso $>$. access on 26 Feb. 2010. doi: $10.1590 / \mathrm{S} 1415-790 X 2004000400010$

MASCARENHAS, B. M. et al. (2009) Estudo de anofelinos antropofílicos peridomiciliares da Praia da Saudade na Ilha de Cotijuba: uma área endêmica de malária em Belém, Pará. Acta Amaz., Manaus, v. 39, n. 2, Available from $<$ http://www.scielo.br/scielo.php?script=sci_arttext\&pid=S0044-59672009000200026 $\& \operatorname{lng}=$ en $\& n r m=i s o>$. access on 26 Feb. 2010. doi: 10.1590/S004459672009000200026

MEDRONHO, R.A. (1999) Avaliação do método geoestatístico na distribuição espacial da hepatite A [tese de doutorado]. Rio de Janeiro: Escola Nacional de Saúde Pública, Fundação Oswaldo Cruz

MELO, O. (2008) A comunidade e a construção do lugar na Ilha de Cotijuba (PA). Programa de Pós- graduação em Geografia - PPGEO/UFPA, EGPA (Escola de Governo do Estado do Pará) 


\section{Revista TECCEN — volume 3 - número 1 - abril de 2010 - ISSN 1984-0993}

MS - Ministério da Saúde (2005) Guia de Vigilância Epidemiológica. 6.ed. 816 p. ISBN 85-334-1047-6 - Brasília

NASCIMENTO, R. (2002) Oficina De Sensibilização Sobre Os Problemas Ambientais Da Ilha De Cotijuba. Ministério da Ciência e Tecnologia. Museu Paraense Emílio Goeldi. Belém, Pará

ORTIZ, J. L. (2003) Emprego do geoprocessamento no estudo da relação entre potencial produtivo de um povoado de eucalipto e atributos do solo e do relevo. Tese de mestrado da Escola Superior de Agricultura Luiz de Queiroz. Piracicaba. p.02.

Sepof - SECRETARIA DE ESTADO DE PLANEJAMENTO ORÇAMENTO E FINANÇAS. (2008) Estatística municipal de Belém. Disponível em $<$ http://www.sepof.pa.gov.br> Belém, Governo do Estado do Pará.

SMITH, K. L. (1988) Selenium in dairy cattle: Its role in disease resistance. Veterinary Medicine - Food-Animal pratice, The Ohio State University, january, v.83, n.1, p.7278.

VEIGA, N. (2005) Modelo de Estruturação do Banco Georreferenciado de dados Ambientais, Epidemiológicos e Socioeconômico de Bragança-Pa. Relatório técnico, IEC/SVS/MS. Belém.

VEIGA, N. (2001) Modelo de Recuperação de Informações Temáticas Inter-Relacionadas, Contidas em Imagens de Satélites, Baseado em Descritores Contextuais. Tese de doutorado. UnB. Brasília-DF. 225p. 